\title{
WOLVES ON THE SOUTHERN SASKATCHEWAN BORDER
}

\section{TOM WHITE, 2580 Retallack Street, Regina, Saskatchewan S4T 2L4}

In historic times packs of wolves followed the buffalo herds and were a major source of predation on the weak, sick and lame. In the period of settlement and the disappearance of the buffalo the wolf was remorselessly hunted because of predation on livestock and the general antipathy towards it. It was also hunted as a sport and for a trophy, at a time when there were fewer forms of entertainment than today. The anecdotes of the early ranchers contain many stories of the wolf hounds which were trained to hunt in the pioneer and ranching settlement area.

In the last 15 years there have been increasing reports of wolves in southern Saskatchewan and there have been suggestions that the buffalo wolf or lobo wolf may still exist. The Montana authorities have reported numerous wolves along the Frenchman Creek south of the Cypress Hills. The cry of the wolf has been heard in the Cypress Hills recently, where it has not been heard for 50 years.

In the Frenchman Creek, Shaunavon, and the Big Muddy areas there have been further reports, as well as in the Avonlee Badlands, approximately 30 miles from Regina. There have been frequent reports of wolves being killed, but until recently no skulls have been obtained to verify the reports. There is always the possibility of reports of wolves being confused with feral dogs

In the summer of 1976 I was able to examine the skull of a wolf which was killed on the Alberta side of the Cypress Hills south of Elkwater, which was mounted inside a perspex case by the Alberta government and then returned to the owner.

We were fortunate to obtain a wolf skull from Mr. Gilchrist, a rancher in the southern Cypress Hills area, where

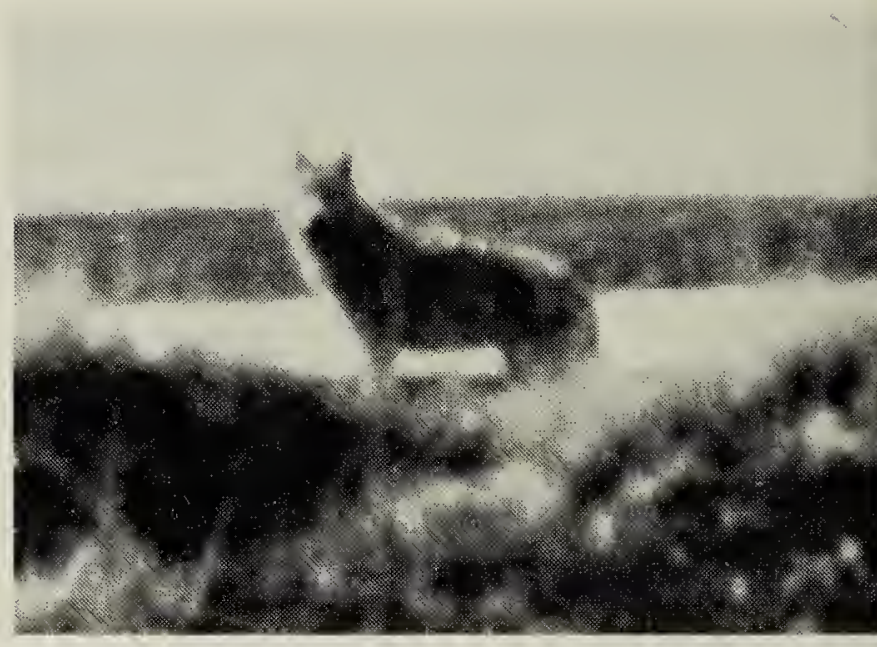

Wolf

M. A. Collop

it had been recently killed. Through Dr. John E. Storer of the Saskatchewan Museum, the skull was forwarded to Dr. C. G. van Zyll de Long, the curator of mammals in the National Museum in Ottawa, for subspecies determination. The reply which we received was that it does not appear to be that of Canis lupus nubilis, the buffalo wolf, and that it falls within the normal wolf subspecies of the north and west.

A study has been made by the Canadian Wildlife Service of various wolves in Banff, Jasper, Prince Albert and Riding Mountain National Parks to establish if there are any remnant groups of the buffalo wolf. It would appear, however, that the specimen obtained recently in the Cypress Hills did not belong to that subspecies, nor do those of the national parks.

It appears certain that there are small numbers of wolves in southern Saskatchewan and that they may break cover from time to time. It is unlikely that they will become numerically abundant, but they may be a further example of how a species can return to an area following rural depopulation and the increase in certain prey species. The reduction in the use of poison bait may also be a factor. 